\title{
Treatment With Mifepristone Allows a Patient With End-stage Pancreatic Cancer in Hospice on a Morphine Drip to Restore a Decent Quality of Life
}

\author{
JEROME H. CHECK ${ }^{1,2}$, DIANE CHECK ${ }^{2}$, MAYA D. SRIVASTAVA ${ }^{3}$, TRINA PORETTA ${ }^{4}$ and JAMES K. AIKINS ${ }^{5}$ \\ ${ }^{1}$ Department of Obstetrics and Gynecology, Division of Reproductive Endocrinology \& Infertility, \\ Cooper Medical School of Rowan University, Camden, NJ, U.S.A.; \\ ${ }^{2}$ Cooper Institute for Reproductive Hormonal Disorders, P.C., Mt. Laurel, NJ, U.S.A.; \\ ${ }^{3}$ Department of Medicine, Division of Allergy and Immunology, \\ State University of New York (SUNY) at Buffalo, Buffalo, NY, U.S.A.; \\ ${ }^{4}$ Kennedy Medical Campus, Sewell, NJ, U.S.A.; \\ ${ }^{5}$ Division of Gynecologic Oncology, Cooper Medical School of Rowan University, Camden, NJ, U.S.A.
}

\begin{abstract}
Background: There is evidence that a unique immunomodulatory protein, known as the progesterone induced blocking factor (PIBF), is utilized by a large variety of cancers to escape immune surveillance. Mifepristone, a progesterone receptor antagonist/modulator, anecdotally, has been found to increase both length and quality of life in many different types of advanced cancers. Case Report: Though there was one previous case of pancreatic cancer that showed a significant reduction in pain for the one month she took mifepristone before changing to an experimental drug, the case presented here provided much greater evidence that this drug can markedly improve both length and quality of life, in at least some patients, with very advanced pancreatic cancer. Conclusion: It is hoped that this case report will influence others to prescribe mifepristone off-label and hopefully substantiate this finding of marked palliative benefit in the majority of a larger series of patients.
\end{abstract}

Pancreatic cancer has one of the highest mortality rates among all malignancies, with a 5-year survival rate of about $20 \%$ (13 ). There are multiple reasons for the poor prognosis of patients

This article is freely accessible online.

Correspondence to: Jerome H. Check, MD, Ph.D., Department of Obstetrics and Gynecology, Division of Reproductive Endocrinology \& Infertility, Cooper Medical School of Rowan University, 7447 Old York Road, Melrose Park, PA 19027, U.S.A. Tel: +1 2156354156, Fax: +1 2156352304, e-mail: laurie@ccivf.com

Key Words: Pancreatic cancer, progesterone receptor antagonists, progesterone induced blocking factor, immunosurveillance, palliation, natural killer cells. with pancreatic cancer, including the failure to present with symptoms until the cancer has already reached an advanced stage, thus precluding early detection (4). Other factors include the aggressive nature of the pancreatic cancer itself, and the lack of highly successful chemotherapy or immunotherapy (5).

The best treatment for pancreatic cancer is surgical resection. However, because of the poor early detection, by the time a patient with pancreatic cancer is diagnosed, surgical options are only available to $15-20 \%$ of patients, contributing to the very poor 5-year survival (6). Unfortunately, even when the surgeon is satisfied that the entire tumor was successfully resected, there is only a median survival of 15-20 months, and a 5-year survival of $8-15 \%$, since extensive micrometastases have already occurred at the time of diagnosis, leading to a high rate of distal and/or local recurrence (6). Thus, consideration has been given to the use of adjuvant chemotherapy, especially with either 5-fluorouracil and folinic acid or gemcitabine, added to surgical resection, at least in the minority of cases when surgical resection is possible (7-10).

Recently, multi-agent chemotherapy has been tried for the minority of pancreatic cancers that are resectable. Combination chemotherapy regimens have been tried with fluorouracil, folinic acid, irinotecan, and oxaliplatin (mFOLFIRINOX). One study showed a median disease-free survival of 21.6 months, but only 17.8 months in the group that was treated with gemcitabine. Median overall survival for the mFOLFIRINOX group was 54.4 months vs. 35 months in the group using gemcitabine as adjuvant therapy (11). Some of the treatment regimens with gemcitabine have also employed multiagent combination therapy including albumin-based paclitaxel, capecitabine, and capecitabine and cisplatin, especially in cases of $B R C A 1 / 2$ or $P A L B 2$ genetic 
mutations (11). However, even the minority of patients that have a resectable tumor, and are fit for multiagent chemotherapy, have a significant morbidity from side effects of chemotherapy with $76 \%$ of patients having grade 3-4 toxicosis with mFOLFIRINOX and $53 \%$ with gemcitabine (11). While chemotherapy has been recommended by various guidelines to be employed even for advanced unresectable pancreatic cancer, it is universally accepted that there are low response rates and high toxicity rates.

Mifepristone, a progesterone receptor antagonist/ modulator has been demonstrated to provide palliative beneficial effects for patients with a variety of advanced cancers that were resistant to standard anticancer therapy (12). Single agent daily oral mifepristone was given to a man with very advanced pancreatic cancer and his outcome is reported in this case report.

\section{Case Report}

A 57-year-old man was admitted to the hospital for severe abdominal pain, and vomiting (25 time per day), along with dyspnea on exertion, and weakness. He was found to have extensive pancreatic cancer. His oncologist advised him that the cancer was so extensive that there was no anti-cancer therapy that could be rendered. He was advised that hospice was the only solution.

He was hospitalized on a morphine drip preparing to die within 1-3 weeks. However, his son had a friend who knew of the use of mifepristone therapy for a variety of cancers (12). He was finally taken out of hospice and placed on oral single agent mifepristone $200 \mathrm{mg}$ daily, administered from his home, after obtaining a compassionate use investigational new drug (IND) approval from the United States Food and Drug Administration (FDA).

When a compassionate use IND from the FDA is obtained, generally 3 months of mifepristone is purchased at one time. The drug costs about $\$ 500$ per month, with a discount for patients with cancer from the Danco Pharmaceutical company. He did not have $\$ 1500$, plus it would be wasted if he died 2 weeks later. We agreed to buy it for him and sell him 10 pills at a time.

He was slumped over in a wheelchair when he first presented and was considered ECOG-4. Within 2 months, in taking single agent oral mifepristone $200 \mathrm{mg}$ daily, he had no pain or vomiting, his weakness was much less, and he was able to walk without assistance. After 5 months of therapy he did not require any analgesics or anti-emetics, and only complained of mild dyspnea on exertion, and mild weakness. He was considered ECOG-2.

He became depressed because he was still too weak to go back to work, and still had to live with his son to help him. At nine months his depression worsened, because he was having trouble affording the drug, and he felt that he was a burden to his family. Thus, at nine months, in stable condition, he elected to stop mifepristone therapy. His pain and vomiting returned within 2 weeks, and was placed in hospice once again. He died 2 weeks later.

\section{Discussion}

Pancreatic cancer is not known to be associated with the classic nuclear progesterone receptor, so one might wonder why would a progesterone receptor modulator be effective in causing improvement in length and quality of life in a moribund man with very advanced pancreatic cancer? A hypothesis was provided in 2001, that malignant tumors may evade immune surveillance by using similar mechanisms as does the fetal-placental unit (13). A series of cancer cell line studies, and controlled animal studies, supported the concept that a key immunomodulatory protein, known as the progesterone induced blocking factor (PIBF), made by embryonic, mesenchymal, and trophoblast cells of the fetal placental unit, and the cancer cells themselves, is secreted into the fetal or tumor microenvironment, and consequently, suppresses cellular immune immunosurveillance, especially, but not limited to, natural killer cells (14-20).

Cancer cell line studies have demonstrated that progesterone can up-regulate mRNA and the immunomodulatory PIBF protein itself, and the progesterone receptor antagonist/ modulator mifepristone can suppress both the mRNA and protein levels of $\operatorname{PIBF}(14,15)$. There is evidence that the $\mathrm{P}$ receptor responsible for PIBF production is a membrane receptor $(21,22)$. Though there is the possibility that the $\mathrm{P}$ membrane receptor responsible for PIBF production may use a different mechanism for activating this receptor other than $\mathrm{P}$ secretion, studies have shown that the $\mathrm{P}$ receptor modulator mifepristone can suppress PIBF production by cancer cells, even in males who do not make progesterone (as evidenced by controlled murine cancer studies) (23). Controlled murine cancer studies support the anti-tumor action of mifepristone against a membrane $\mathrm{P}$ receptor by showing efficacy in controlled studies of murine cancers that are not known to be associated with the classic nuclear $\mathrm{P}$ receptor $(24,25)$.

Indeed, mifepristone has been found to provide improved longevity and quality of life in very advanced human cancers not known to be associated with the classic nuclear $\mathrm{P}$ receptor, many of which, prior to mifepristone therapy, had also shown significant progression despite standard therapy $(12,21,22)$. These cancers have included colon cancer, thymic epithelial cell carcinoma, leiomyosarcoma, transitional cell carcinoma of the renal pelvis, and glioblastoma multiforme grade IV $(12,26,27)$.

Mifepristone has provided marked extension and quality of life in patients with advanced lung cancer where there is no known association with the classic nuclear $\mathrm{P}$ receptor (22). Single agent mifepristone, not only in a short period of time 
improved low PO2 and severe hyponatremia in a woman with very advanced probable small cell lung cancer but provided a marked extension of a high quality of life (28). For non-small cell lung cancer (NSCLC) mifepristone provided marked palliative benefits, and increased length of life, in patients with chemotherapy and immunotherapy resistant advanced lung cancers that were either not associated with any tumor markers, or were associated with the programmed death factor-1, or the epidermal growth factor receptor mutation (29-31). All 4 of these NSCLC patients had brain metastasis, and all 4 progressed despite standard chemotherapy (29-31). One of the patients progressed despite addition of nivolumab prior to mifepristone therapy, and two progressed despite treatment with the thirdgeneration tyrosine kinase inhibitor, osimertinib $(30,31)$.

Mifepristone has also been found to allow a high quality 17 years of life (and still alive and doing well) to a man with multifocal renal cell carcinoma, who only wanted one renal sparing surgical procedure followed by $200 \mathrm{mg}$ oral single agent mifepristone (32). This latter case is important because it shows that mifepristone can inhibit cancer progression even when the tumor is not at the very aggressive (possibly stem cell) stage (32). Interestingly, his diabetes caused kidney failure 11 years after he had been taking mifepristone. At that time, he consented to a bilateral nephrectomy. He was approved for a kidney transplant, and he decided to stop mifepristone despite immunosuppressant therapy to prevent kidney rejection. No metastases have developed in six years without mifepristone (33).

There was another case report of a 58-year-old woman with stage IV pancreatic cancer who progressed despite gemcitabine and erlotinib and then, capecitabine plus oxaliplatin. The chemotherapy was stopped. She was placed on palliative care, taking high dosages of narcotics to relieve severe pain. After taking $200 \mathrm{mg}$ single agent oral mifepristone, she had marked relief of pain, leading to a marked reduction in narcotic dosage, within the first two weeks of mifepristone therapy, which continued for 4 weeks. However, she was approved for a phase I clinical trial of an experimental drug at a major cancer institute, so she stopped mifepristone, and started this new experimental drug. She died within 2 days due to cardiac complications of this new drug (12).

Though mifepristone was not found to be particularly effective for unresectable meningiomas, the daily use of mifepristone for long periods of time, in a large number of patients, was found to be very well tolerated, with little or no side effects (33). Based on this case report, and the lack of effective chemotherapy or immunologic agents for advanced pancreatic cancer, it seems reasonable to consider mifepristone as first line therapy for unresectable pancreatic cancer. Possibly, the drug could be considered for patients with resectable pancreatic cancers to help prevent spread or local recurrence, since present-day therapies only provide moderate extension of life with a lot of side effects.
Though the $200 \mathrm{mg}$ dosage of mifepristone is not approved for treating cancer but its approved use is as an abortifacient (probably related to immune rejection of the fetus related to suppressing PIBF), it is available in the United States only by obtaining a compassionate use IND application for each patient. The IND process has been markedly simplified. Though off-label use of most drugs is generally granted without an IND to treating physicians, because of the sensitivity of many people in the world toward therapeutic abortion, the IND serves to inhibit easy use of the drug to terminate pregnancy.

Hopefully, this manuscript will prompt other treating physicians to consider using use mifepristone off-label, and hopefully other experiences will support the conclusions of this case report. Possibly, this case could generate interest in a large prospective trial potentially identifying a subset of patients with pancreatic cancer who will respond to progesterone receptor antagonists, which if showing similar positive results, could influence the Food and Drug Administration to drop the requirement for a compassionate use IND (at least for pancreatic cancer) or could lead health care providers to consider paying for the drug. At present, in the United States it costs about $\$ 15$ a pill, but it is much cheaper in other parts of the world. Pancreatic cancer can thus be added to the long list of a variety of advanced cancers for which mifepristone has provided significant palliative benefit (34).

\section{Conflicts of Interest}

The Authors have no conflicts of interest to declare regarding this study.

\section{Authors' Contributions}

The majority of the manuscript was written by the lead author. Modifications of the manuscript were made by the other authors. Diane Check runs the clinical cancer studies. Trina Poretta and James Aikins also served as oncology consultants during the patient's treatment.

\section{References}

1 Kamisawa T, Wood LD, Itoi T and Takaori K: Pancreatic cancer. Lancet 388: 73-85, 2016. PMID: 26830752. DOI: 10.1016/ S0140-6736(16)00141-0

2 Rawla P, Sunkara T and Gaduputi V: Epidemiology of Pancreatic Cancer: Global Trends, Etiology and Risk Factors. World J Oncol 10(1): 10-27, 2019. PMID: 30834048. DOI: 10.14740/wjon1166

3 Huang L, Jansen L, Balavarca Y, Babaei M, van der Geest L, Lemmens V, Van Eycken L, De Schutter H, Johannesen TB, Primic-Žakelj M, Zadnik V, Besselink MG, Schrotz-King P and Brenner H: Stratified survival of resected and overall pancreatic cancer patients in Europe and the USA in the early twenty-first century: a large, international population-based study. BMC Med 16(1): 125, 2018. PMID: 30126408. DOI: 10.1186/s12916-018$1120-9$ 
4 Kaur S, Baine MJ, Jain M, Sasson AR and Batra SK: Early diagnosis of pancreatic cancer: challenges and new developments. Biomark Med 6(5): 597-612, 2012. PMID: 23075238. DOI: $10.2217 / \mathrm{bmm} .12 .69$

5 Zeng S, Pöttler M, Lan B, Grützmann R, Pilarsky C and Yang $\mathrm{H}$ : Chemoresistance in pancreatic cancer. Int J Mol Sci 20(18): 4504, 2019. PMID: 31514451. DOI: 10.3390/ijms20184504

6 Ducreux M, Cuhna AS, Caramella C, Hollebecque A, Burtin P, Goéré D, Seufferlein T, Haustermans K, Van Laethem JL, Conroy T, Arnold D and ESMO Guidelines Committee: Cancer of the pancreas: ESMO Clinical Practice Guidelines for diagnosis, treatment and follow-up. Ann Oncol 26(5): v56-68, 2015. PMID: 26314780. DOI: 10.1093/annonc/mdv295

7 Lutfi W, Talamonti MS, Kantor O, Wang CH, Liederbach E, Stocker SJ, Bentrem DJ, Roggin KK, Winchester DJ, Marsh R, Prinz RA and Baker MS: Perioperative chemotherapy is associated with a survival advantage in early stage adenocarcinoma of the pancreatic head. Surgery 160(3): 714724, 2016. PMID: 27422328. DOI: 10.1016/j.surg.2016.05.029

8 Neoptolemos JP, Stocken DD, Tudur Smith C, Bassi C, Ghaneh P, Owen E, Moore M, Padbury R, Doi R, Smith D and Büchler MW: Adjuvant 5-fluorouracil and folinic acid vs. observation for pancreatic cancer: composite data from the ESPAC-1 and -3(v1) trials. Br J Cancer 100(2): 246-250, 2009. PMID: 19127260. DOI: $10.1038 /$ sj.bjc.6604838

9 Oettle H, Post S, Neuhaus P, Gellert K, Langrehr J, Ridwelski K, Schramm H, Fahlke J, Zuelke C, Burkart C, Gutberlet K, Kettner E, Schmalenberg H, Weigang-Koehler K, Bechstein WO, Niedergethmann M, Schmidt-Wolf I, Roll L, Doerken B and Riess $\mathrm{H}$ : Adjuvant chemotherapy with gemcitabine vs. observation in patients undergoing curative-intent resection of pancreatic cancer: a randomized controlled trial. JAMA 297(3): 267-277, 2007. PMID: 17227978. DOI: 10.1001/jama.297.3.267

10 Lambert A, Schwarz L, Borbath I, Henry A, Van Laethem JL, Malka D, Ducreux M and Conroy T: An update on treatment options for pancreatic adenocarcinoma. Ther Adv Med Oncol 11: 1758835919875568, 2019. PMID: 31598142. DOI: $10.1177 / 1758835919875568$

11 Khorana AA, McKernin SE, Berlin J, Hong TS, Maitra A, Moravek C, Mumber M, Schulick R, Zeh HJ and Katz MHG: Potentially curable pancreatic adenocarcinoma: ASCO Clinical Practice Guideline Update. J Clin Oncol 37(23): 2082-2088, 2019. PMID: 31180816. DOI: 10.1200/JCO.19.00946

12 Check JH, Dix E, Cohen R, Check D and Wilson C: Efficacy of the progesterone receptor antagonist mifepristone for palliative therapy of patients with a variety of advanced cancer types. Anticancer Res 30(2): 623-628, 2010. PMID: 20332480.

13 Check JH, Nazari P, Goldberg J, Yuen W and Angotti D: A model for potential tumor immunotherapy based on knowledge of immune mechanisms responsible for spontaneous abortion. Med Hypotheses 57(3): 337-343, 2001. PMID: 11516226. DOI: 10.1054/mehy.2001.1333

14 Lachmann M, Gelbmann D, Kálmán E, Polgár B, Buschle M, Von Gabain A, Szekeres-Barthó $J$ and Nagy E: PIBF (progesterone induced blocking factor) is overexpressed in highly proliferating cells and associated with the centrosome. Int J Cancer 112(1): 51-60, 2004. PMID: 15305375. DOI: $10.1002 / \mathrm{ijc} .20326$

15 Srivastava MD, Thomas A, Srivastava BI and Check JH: Expression and modulation of progesterone induced blocking factor (PIBF) and innate immune factors in human leukemia cell lines by progesterone and mifepristone. Leuk Lymphoma 48(8): 1610-1617, 2007. PMID: 17701593. DOI: 10.1080/1042819070 471999

16 Check JH, Dix E and Sansoucie L: Support for the hypothesis that successful immunotherapy of various cancers can be achieved by inhibiting a progesterone associated immunomodulatory protein. Med Hypotheses 72(1): 87-90, 2009. PMID: 18842348. DOI: 10.1016/j.mehy.2008.05.042

17 Check JH and Cohen R: The role of progesterone and the progesterone receptor in human reproduction and cancer. Expert Rev Endocrinol Metab 8(5): 469-484, 2013. PMID: 30754194. DOI: $10.1586 / 17446651.2013 .827380$

18 Check JH, Arwitz M, Gross J, Szekeres-Bartho J and Wu CH: Evidence that the expression of progesterone-induced blocking factor by maternal T-lymphocytes is positively correlated with conception. Am J Reprod Immunol 38(1): 6-8, 1997. PMID: 9266004. DOI: 10.1111/j.1600-0897.1997.tb00269.x

19 Cohen RA, Check JH and Dougherty MP: Evidence that exposure to progesterone alone is a sufficient stimulus to cause a precipitous rise in the immunomodulatory protein the progesterone induced blocking factor (PIBF). J Assist Reprod Genet 33(2): 221-229, 2016. PMID: 26634256. DOI: 10.1007/s10815-015-0619-7

20 Szekeres-Bartho J and Polgar B: PIBF: the double-edged sword. Pregnancy and tumor. Am J Reprod Immunol 64(2): 77-86, 2010. PMID: 20367622. DOI: 10.1111/j.1600-0897.2010.00833.x

21 Check JH and Check D: Therapy aimed to suppress the production of the immunosuppressive protein progesterone induced blocking factor (PIBF) may provide palliation and/or increased longevity for patients with a variety of different advanced cancers - A Review. Anticancer Res 39(7): 3365-3372, 2019. PMID: 31262857. DOI: 10.21873/anticanres.13479

22 Check JH: The role of progesterone and the progesterone receptor in cancer. Expert Rev Endocrinol Metab 12(3): 187-197, 2017. PMID: 30063455. DOI: 10.1080/17446651.2017.1314783

23. Check JH, Dix E, Wilson C and Check D: Progesterone receptor antagonist therapy has therapeutic potential even in cancer restricted to males as evidenced from murine testicular and prostate cancer studies. Anticancer Res 30: 4921-4924, 2010. PMID: 21187471.

24 Check JH, Sansoucie L, Chern J, Amadi N and Katz Y: Mifepristone treatment improves length and quality of survival of mice with spontaneous leukemia. Anticancer Res 29(8): 29772980, 2009. PMID: 19661303.

25 Check JH, Sansoucie L, Chern J and Dix E: Mifepristone treatment improves length and quality of survival of mice with spontaneous lung cancer. Anticancer Res 30(1): 119-122, 2010. PMID: 20150625.

26 Check JH, Dix E, Sansoucie L and Check D: Mifepristone may halt progression of extensively metastatic human adenocarcinoma of the colon - case report. Anticancer Res 29(5): 1611-1613, 2009. PMID: 19443374.

27 Check JH, Wilson C, Cohen R and Sarumi M: Evidence that mifepristone, a progesterone receptor antagonist, can cross the blood brain barrier and provide palliative benefits for glioblastoma multiforme grade IV. Anticancer Res 34(5): 23852388, 2014. PMID: 24778047.

28 Check JH, Check D, Wilson C and Lofberg P: Long-term highquality survival with single-agent mifepristone treatment despite 
advanced cancer. Anticancer Res 36(12): 6511-6513, 2016. PMID: 27919975. DOI: 10.21873/anticanres.11251

29 Check DL and Check JH: Significant palliative benefits of single agent mifepristone for advanced lung cancer that previously failed standard therapy. Med Clin Sci 1(2): 1-5, 2019.

30 Check JH, Check D and Poretta T: Mifepristone extends both length and quality of life in a patient with advanced non-small cell lung cancer that has progressed despite chemotherapy and a check-point Inhibitor. Anticancer Res 39(4): 1923-1926, 2019. PMID: 30952734. DOI: 10.21873/anticanres.13301

31 Check DL, Check JH, Poretta T, Aikins J and Wilson C: Prolonged high-quality life in patients with non-small cell lung cancer treated with mifepristone who advanced despite osimertinib. Cancer Sci Res 3(2): 1-5, 2020.

32 Check DL, Check JH and Poretta T: Conservative laparoscopic surgery plus mifepristone for treating multifocal renal cell carcinoma. Cancer Sci Res 3(2): 1-4, 2020.
33. Spitz IM, Grunberg SM, Chabbert-Buffet N, Lindenberg T, Gelber $\mathrm{H}$ and Sitruk-Ware R: Management of patients receiving longterm treatment with mifepristone. Fertil Steril 84(6): 1719-1726, 2005. PMID: 16359971. DOI: 10.1016/j.fertnstert.2005.05.056

34 Check JH and Check D: Progesterone and glucocorticoid receptor modulator mifepristone (RU-486) as treatment for advanced cancers [Online First], IntechOpen. Available at: https://www.intechopen.com/online-first/progesterone-andglucocorticoid-receptor-modulator-mifepristone-ru-486-astreatment-for-advanced-can [Last accessed September 4, 2020]

Received October 17, 2020

Revised October 31, 2020

Accepted November 4, 2020 